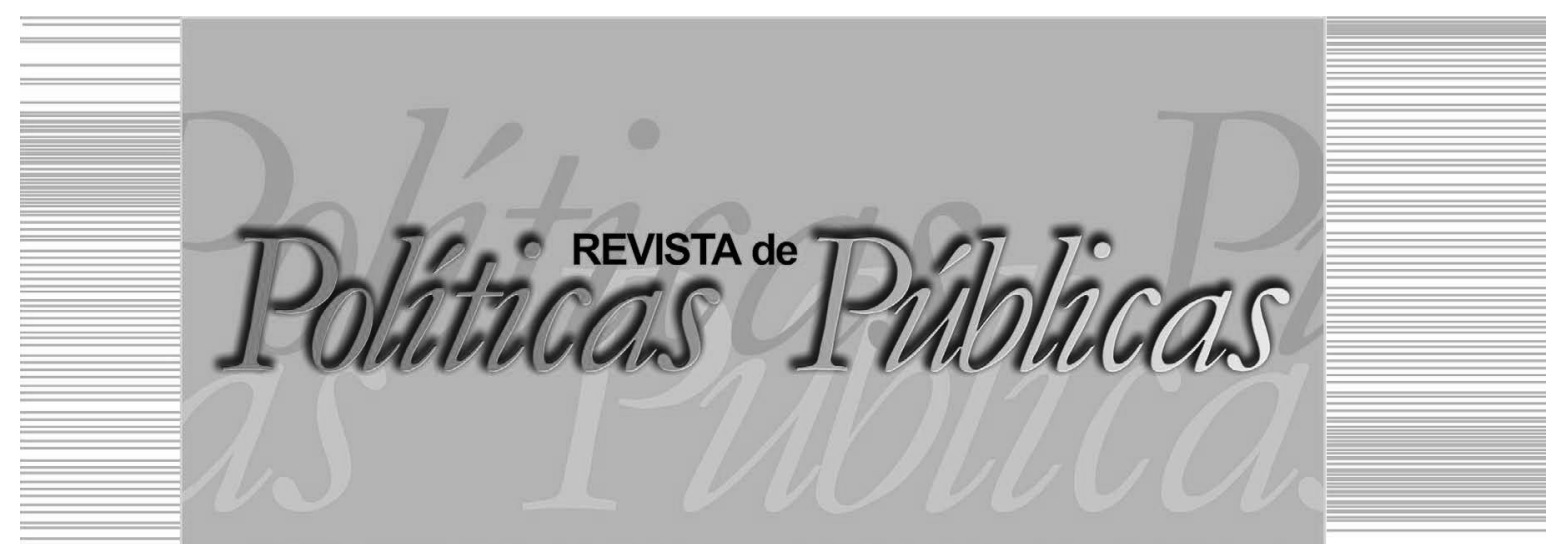

\title{
FUNDO PÚBLICO E A USURPAÇÃO DOS DIREITOS DO TRABALHO NA ATUALIDADE
}

\author{
Giselle Souza da Silval \\ Isabel Cristina Lopes Barbosa ${ }^{2}$ \\ Edite Alves Azevedo ${ }^{3}$ \\ Hugo Cordeiro Mota Pinheiro ${ }^{4}$
}

\section{Resumo}

O presente artigo tem como objetivo analisar a centralidade do fundo público no capitalismo contemporâneo e como o mesmo vem sendo expropriado pelo capital por meio das contrarreformas que atacam direitos do trabalho historicamente conquistados. Busca apresentar a relevância do fundo público desde a fase tardia do capitalismo para a garantia das condições gerais de acumulação do capital, tanto na reprodução da força de trabalho quanto ao propiciar, direta e indiretamente, a lucratividade. Analisa também os impactos da crise política econômica atual para o fundo público, como se configuram as contrarreformas propostas e os reflexos que poderão ter na vida dos trabalhadores. Conclui que o fundo público se coloca no cenário atual como a alternativa para a saída da crise e retomada dos superlucros do grande capital. Palavras-chave: Fundo Público, crise do capital, contrarreformas do Estado.

\footnotetext{
Assistente Social, Doutora em Serviço Social pela Universidade do Estado do Rio de Janeiro (UERJ), Professora Adjunta da Universidade Federal do Estado do Rio de Janeiro (UNIRIO). E-mail: gigissrj@gmail.com.

2 Graduanda em Serviço Social pela Universidade Federal do Estado do Rio de Janeiro (UNIRIO). Bolsista CNPQ. E-mail: isabelclbarbosa@gmail.com.

3 Graduanda em Serviço Social pela Universidade Federal do Estado do Rio de Janeiro (UNIRIO). Bolsista CNPQ. E-mail: edite.alvesazevedo4@gmail.com.

4 Graduando em Serviço Social pela Universidade Federal do Estado do Rio de Janeiro (UNIRIO). Bolsista CNPQ. E-mail: hugo_cordeiro104@hotmail.com / Universidade Federal do Estado do Rio de Janeiro - UNIRIO: Av. Pasteur, 296 - Urca - Rio de Janeiro. CEP: 22290-240.
} 


\title{
PUBLIC FUND AND THE USURPATION OF CURRENT WORK RIGHTS
}

\begin{abstract}
This article aims to analyze the centrality of the public fund in contemporary capitalism and how it has been expropriated by capital through the reforms that attack historically conquered labor rights. We will seek to present the relevance of the public fund from the late phase of capitalism to the guarantee of the general conditions of accumulation of capital, both in the reproduction of the workforce and in providing direct and indirect profitability. It also analyzes the impacts of the economic and current political crisis on the public fund, as well as the proposed reforms and the impacts they may have on workers' lives. Concludes that the public fund is placed in the current scenario as the alternative for the exit of the crisis and resumption of the super-capitals of the great capital.
\end{abstract}

Key words: Public fund, capital crisis, State reforms.

\section{INTRODUÇÃO}

O estudo do fundo público e os ataques pelos quais passam as políticas sociais nos dias de hoje precisam ser compreendidos a partir da análise histórico-crítica sobre as crises estruturais e conjunturais do capital e os impactos numa sociedade periférica e dependente como a brasileira. Este artigo tem o objetivo de estudar as transformações pelas quais passa nossa sociedade e os impactos que a crise política e econômica atual produz nas políticas sociais voltadas à reprodução da força de trabalho. Pretendemos analisar brevemente como o fundo público passa a ser o mecanismo de atenuar os efeitos desta crise e como as contrarreformas ${ }^{1}$ em curso serão nocivas para os trabalhadores ${ }^{2}$.

O papel do fundo público na contemporaneidade deve ser analisado a partir da apreensão crítica, capaz de investigar as múltiplas determinações que atuam no processo de expropriação e financeirização da vida social em tempos atuais. Para tanto, nos embasamos na tradição marxista e sua análise da formação social brasileira. Toma-se como de extrema relevância a desmistificação do desenvolvimento capitalista numa sociedade periférica e dependente para compreender como se configura a correlação de forças presente.

Numa sociedade como a brasileira, em que os direitos sociais são limitados e atualmente apresentam dificuldades de serem 
mantidos dada a correlação de forças, é preciso estudar as disputas por trás do fundo público. Temos uma tributação regressiva, visto que a classe trabalhadora é a mais onerada com os tributos indiretos e estes são os maiores financiadores das políticas públicas; por isso, torna-se fundamental compreender o que o Estado faz com esses recursos que deveriam ser destinados à reprodução social da força de trabalho.

Partindo da premissa de que só o trabalho cria valor, e nesta sociedade valoriza o capital, tal expropriação dos frutos do trabalho deve ser analisada à luz da teoria crítica e do método do materialismo histórico dialético, para entender como os frutos do trabalho são distribuídos na sociedade contemporânea. Compreender esse processo de apropriação do trabalho excedente e do trabalho necessário é tarefa fundamental para lutar por direitos sociais, por redistribuição da riqueza socialmente produzida àqueles que dela são expropriados e acumular forças na construção de outra sociedade possível.

Pretendemos, então, estudar de forma preliminar esse processo contrarreformista em curso, as orientações dadas ao fundo público pelo capital em tempos de crise e como isso afetará as políticas sociais e os trabalhadores nos próximos anos.

\section{FUNDO PÚBLICO, CRISE DO CAPITAL E A CRISE POLÍTICA ATUAL}

O fundo público só pode ser entendido do ponto de vista histórico. O capitalismo tardio tem como característica a "[...] combinação simultânea da função diretamente econômica do Estado burguês, do esforço para despolitizar a classe operária e do mito de uma economia onipotente.” (MANDEL, 1982, p. 341). A ampliação da intervenção direta do Estado coloca o fundo público no patamar de componente estrutural e insubstituível para o capital no capitalismo contemporâneo, de que trata Oliveira (1998).

Se o Estado sempre foi um ente fundamental para o desenvolvimento do capital, desde a garantia dos princípios liberais de propriedade privada e manutenção da ordem burguesa, no capitalismo maduro se tornará instrumento fundamental no desenvolvimento das relações de produção capitalistas, portanto, sua imprescindibilidade ao capital é de caráter estrutural, tanto para manutenção da sua acumulação quanto para reprodução da força 
de trabalho. Precisamos compreender as mudanças ocorridas no capitalismo monopolista na sua fase madura para entender como se constrói o fundo público e quais as novas requisições postas ao Estado.

Segundo Francisco de Oliveira (1998), no capitalismo em sua fase madura, o fundo público se tornará pressuposto do financiamento da acumulação do capital e da reprodução da força de trabalho, necessário antes mesmo de iniciar o processo de produção, ou seja, imprescindível para o capital. Para o autor, o fundo público será imprescindível, um componente estrutural e insubstituível para o capital e "[...] o financiamento público contemporâneo tornou-se abrangente, estável e marcado por regras assentidas pelos principais grupos sociais e políticos." (OLIVEIRA, 1998, p. 21).

Behring (2010, p. 20) define a composição do fundo público como uma punção compulsória, na forma de impostos, contribuições e taxas, da mais-valia socialmente produzida, "[...] ou seja, é parte do trabalho excedente que se metamorfoseou em lucro, juro ou renda da terra e que é apropriado pelo Estado para o desempenho de múltiplas funções".

Mas a complexificação dessa atuação estatal no desenvolvimento capitalista levará o fundo público a socializar cada vez mais os custos com a reprodução do capital e do trabalho. $\mathrm{O}$ sistema tributário será o mecanismo de formação do fundo público e, no caso brasileiro, se sustentará em grande medida nos e pelos salários. O fundo público se formará, assim, de trabalho excedente, o que quer dizer da mais-valia extraída da exploração do trabalho alheio, e do trabalho necessário, via tributação, que, no contexto brasileiro, é regressiva e onera a classe trabalhadora.

$\mathrm{Na}$ sociedade brasileira, o fundo público advém cada vez mais do trabalho necessário, visto que a tributação regressiva faz com que os impostos indiretos, que recaem sobre o consumo, garantam grande parte de sua composição. A regressividade se deve ao fato de a arrecadação estar pautada majoritariamente nos tributos indiretos que incidem sobre a produção e o consumo, ou seja, os tributos são transferidos para os preços dos produtos adquiridos pelos consumidores. Os dados orçamentários mostram que mais de $60 \%$ das receitas arrecadadas pela União advêm dos trabalhadores assalariados e das classes de menor poder aquisitivo. 
Com isso, quem mais arca com o ônus tributário e, portanto, com o financiamento das políticas públicas, proporcionalmente, é a classe trabalhadora. $\mathrm{O}$ que quer dizer que tanto as políticas de reprodução social do trabalhador quanto a alimentação do capital portador de juros por meio do pagamento da dívida pública advêm majoritariamente de recursos dos trabalhadores.

Ao mesmo tempo, o padrão de acumulação do capital na contemporaneidade está centrado na mundialização, no qual o Estado atenderá em larga escala às demandas do capital financeiro. Ao contrário do discurso neoliberal de Estado mínimo, o Estado assumirá centralidade no processo de produção e reprodução do capital. Segundo Anderson (1995), o Estado neoliberal não pode ser pensado como Estado fraco, ao contrário. Era preciso garantir um Estado forte, sim, em sua capacidade de romper o poder dos sindicatos e no controle do dinheiro, mas parco em todos os gastos sociais e nas intervenções econômicas; estabilidade monetária e fiscal, com contenção de gastos e manutenção de uma taxa natural de desemprego; reformas fiscais com redução de impostos sobre as altas rendas. $\mathrm{O}$ redirecionamento deste Estado o torna mais inchado na atenção às necessidades do capital. Não como tendência natural, mas também fruto da correlação de forças presente no atual período histórico, desfavorável para o mundo do trabalho.

Nos tempos atuais os mecanismos de captura desses recursos pela forma mais fetichizada do capital, o capital financeirizado, têm sido o desmonte dos direitos sociais historicamente constituídos e a financeirização perversa da Seguridade Social, que tem no âmbito orçamentário um dos seus principais instrumentos contrarreformistas. São drenadas do fundo público, o que quer dizer, em grande parte, dos recursos oriundos da classe trabalhadora, grandes somas para a remuneração do capital portador de juros. Isso é feito por meio do capital fictício, forma exacerbada do fetiche do capital portador de juros e que tem na dívida pública sua principal forma de atuação. $\mathrm{O}$ endividamento público tem se tornado um mecanismo de manipulação e controle do Estado de que lança mão a oligarquia burguesa, em meio à correlação de forças presente no cenário contemporâneo a qual se apresenta mais favorável à atenção dos interesses do grande capital.

Se desde a fase madura do capitalismo o fundo público se constitui como central, em tempos de crise sua imprescindibilidade 
fica ainda mais evidente. Um exemplo é o socorro dos estados nacionais aos países centrais na crise iniciada em 2008, na qual trilhões de dólares foram disponibilizados a bancos e empresas em iminência de quebra. A crise mundial dos anos 2008 se caracteriza como mais uma crise do grande capital que tem sua raiz nas contradições fundamentais da ordem sócio-metabólica, dentre elas as dificuldades de resolução da superacumulação diante do subconsumo (MANDEL, 1982) e, como enfatizava Marx já no século XIX, o distanciamento entre os valores reais e imaginários que resultam da supremacia do capital portador de juros. (MARX, 1983).

Tal crise, que parecia ter atingido o país como uma marolinha, segundo uma política adotada pelo governo petista, de garantia de recursos do fundo público para manter a lucratividade do capital, chega agora como um tsunami.

O governo Dilma chega ao poder aplicando o chamado novo desenvolvimentismo e adota medidas anticíclicas para blindar a economia da crise recente, ancorando-se no desenvolvimento do capital produtivo, em grande medida no setor de commodities que evidencia o tipo de novo desenvolvimento mantido. $O$ fundo público será usado em grande parte para manter o crescimento econômico, a estabilidade monetária e fiscal e a lucratividade direta das formas de capital (produtivo-industrial e financeiro-fictício).

A partir de 2013, a crise política e a crise econômica eclodem no país, e a forma buscada pelo capital será mais fundo público para salvá-lo, empreendendo uma ofensiva em direção aos direitos sociais até então duramente mantidos. Parece-nos adequado identificar a relação entre os projetos empreendidos pelos últimos governos e sua insustentabilidade neste momento pela burguesia hegemônica e autocrática, quando as taxas de lucratividade apresentam queda significativa. $\mathrm{O}$ esgotamento do modelo neodesenvolvimentista se inicia no abandono da política de favorecimento do capital produtivo de base nacional e tem sua coroação no golpe jurídico-midiático. $\mathrm{Na}$ verdade, corresponde aos limites da manutenção o social-liberalismo em períodos de queda das taxas de lucro.

Assim, a onda de ataques aos direitos sociais é o objetivo principal e urgente da burguesia neoliberal e autocrática, começando pelos cortes orçamentários (sociais, já que a dívida se mantém crescente), como educação, saúde, entre outros, avançando em 
direção às reformas trabalhistas (com a aprovação das terceirizações das atividades fim, recentemente) e buscando agora atacar a grande política da Seguridade: a previdência social.

$\mathrm{O}$ processo que colocou em marcha o conjunto de contrarreformas se explica pela crise política institucional associada a uma concomitante convulsão social. Nesse caso, esse processo não se caracterizou necessariamente pela disputa entre projetos políticos distintos, no embate entre os interesses da classe trabalhadora e da burguesia, ou entre as frações das elites nacionais na direção do Estado. Mas, ao contrário, houve o acirramento da disputa políticopartidária entre o Partido dos Trabalhadores (PT) e o Partido da Social Democracia Brasileira (PSDB), cujo objetivo era se garantir como representante do bloco hegemônico da burguesia brasileira, composto pelo setor rentista, da indústria e agronegócio. (DEMIER, 2016).

Essa disputa se concretiza pela aplicação de um mesmo projeto, mas com interface e intensidade distintas. O PSDB se notabilizou durante a década de 1990 por aprofundar durante os oito anos de governo o ajuste neoliberal e privatista, bem como o esmagamento político da classe trabalhadora. Ademais, não houve interesse do governo psdbista em destinar além de uma parte residual do fundo público para o conjunto dos trabalhadores no Brasil.

Diferente do PSDB, o PT surgiu do movimento operário do $\mathrm{ABC}$ paulista e, por isso, mais influente entre os movimentos sociais. Contudo, seguiu a cartilha neoliberal - inscrita na agenda psdbista, rejeitada nas eleições de 2012 -, mesclando a isso a diminuição do desemprego, aumento da formalização do trabalho em alguns setores e expansão do crédito para o consumo popular, além do fomento de programas sociais de cunho assistencialista, seletivista e residual com o objetivo de ampliação do acesso ao consumo e como parte da agenda de redução da pobreza, preconizada pelos organismos internacionais, bem como a abertura de concursos públicos, entre outras medidas.

Ao visar à expansão de sua base social e eleitoral, o PT, nos dez primeiros anos de governo, mesclou contrarreformas, diminuição do desemprego, ampliação de políticas sociais compensatórias e elevação do consumo popular, fez a coadunação eficiente para garantir renda - ainda que mínima - a parcelas significativas da população e atender os interesses das elites brasileiras. As lideranças 
petistas conseguiram fazer algo, talvez inédito, em relação aos partidos políticos da ordem: agradou a elite brasileira com repasse de montantes robustos do fundo público e apassivou o conjunto dos trabalhadores nesse período, uma clara política de conciliação de classes que favoreceu enormemente à burguesia, especialmente a transnacional.

A democracia de cooptação, genialmente antecipada por Florestan, mas por ele descartada como possibilidade, não veio da autorreforma da autocracia, mas inesperadamente, do desenvolvimento da estratégia democrática popular que desloca para o governo um setor que emerge da classe trabalhadora e dela se afasta para negociar em seu nome o pacto que acaba por resolver os problemas de hegemonia que faltava à consolidação do poder burguês no Brasil. (IASI, 2012, p. 316).

Ademais, o PT implementou o programa do PSDB de forma mais eficiente, na medida em que garantiu a conciliação entre as classes, o que provocou o enfraquecimento temporário deste e transformou a oposição psdbista em um grande vazio políticoideológico descolado da realidade das transformações provocadas pelos governos petistas.

Não obstante esse ambiente de calmaria ter se consolidado por quase dez anos, 2013 começa a apresentar sintomas do que hoje é uma convulsão de âmbitos social, político e econômico. Índices econômicos que despencam num curto espaço de tempo, aumento do desemprego e a inflação que compromete o pouco poder de compra conquistado pelos trabalhadores nos governos PT, bem como o dos setores médios do Brasil, se transformaram, junto à carga tributária nacional de cunho regressivo, nos elementos de asfixiamento das camadas médias e dos assalariados. A pressão do grande capital para não sofrer os efeitos deletérios da crise trouxe um cenário de profunda instabilidade no conjunto da sociedade brasileira, sobretudo nas cidades. Houve descontentamento crescente com relação ao aumento brusco do custo de vida, da precarização dos serviços, momento no qual as poucas conquistas dos trabalhadores sofreram retrocesso.

A partir disso, o PT vivenciará os efeitos da crise econômica que conseguiu adiar por alguns anos, articulada à crise política, na qual tanto a burguesia quanto os trabalhadores já demonstravam sinais de descontentamento para com as medidas adotadas desde o governo Dilma. Há um esgotamento da política do novo 
desenvolvimentismo ${ }^{3}$, que trará uma reacomodação do bloco de poder dominante. A realidade que se apresenta após isso é o surgimento, das sombras, da oposição de direita, retirando do ostracismo a extrema-direita e seus congêneres e resgatando todos os ideais de exaltação à ditadura militar e ao livre mercado.

\section{CONTRARREFORMAS DO GOVERNO TEMER E USURPAÇÃO DOS DIREITOS SOCIAIS}

O golpe jurídico-midiático-parlamentar tem como desfecho a chegada do até então vice-presidente Michel Temer ao poder, que incorrerá numa acelerada e avassaladora onda contrarreformista, buscando empreender todas as medidas de interesse do grande capital, bem representados no Congresso Nacional.

Desde as reformas no ensino médio, à escola sem partido, passando pela terceirização, pela Proposta de Emenda à Constituição (PEC) do teto dos gastos públicos, até a contrarreforma trabalhista recentemente aprovada e contrarreforma da previdência, todas se inserem numa ofensiva do grande capital com apoio e aval da burguesia de base nacional, que intentam não só neutralizar o pensamento crítico como quebrar os sindicatos, atacar as políticas sociais (para mercantilizá-las) e fragmentar ainda mais os trabalhadores entre aqueles que podem pagar pela sua aposentadoria por meio de bancos/instituições privadas de previdência e a grande maioria que só depende da previdência pública e terá de trabalhar até o fim da vida para receber parcos recursos.

O governo ilegítimo vem empreendendo contrarreformas de desmonte das políticas sociais e de retirada de direitos, através da aprovação da PEC n ${ }^{\circ} 55$ de 2016 (Teto dos Gastos Públicos) e do Projeto de Lei (PL) no 38 de 2017 (Reforma Trabalhista), além da $\mathrm{PEC} \mathrm{n}^{\circ} 287$, de 5 de dezembro de 2016 (Reforma da Previdência) que embora ainda não tenha sido aprovada, se encontra em tramitação no Legislativo.

Encaminhada ao Congresso Nacional em 16 de julho de 2016, a PEC n $n^{\circ} 55 / 2016$ (BRASIL, 2016a) modifica os artigos $102^{\circ}$ e $105^{\circ}$ do Ato das Disposições Constitucionais Transitórias da Constituição e estabelece um novo regime fiscal. Apelidada por setores da sociedade civil de PEC do Fim do Mundo, ela coloca limites nas despesas primárias por 20 anos, só podendo ser modificada após 10 anos de vigência. Essa proposta de emenda foi precedida por uma 
nova meta fiscal de 2016, que havia sido modificada no governo Dilma, mas reformulada com a chegada de Temer à presidência. Essa nova meta que previa um déficit para o ano já sinalizava que medidas de contenção de despesas estavam por vir.

E seguindo o roteiro, o Ministro da Fazenda em exercício declara que o problema tem raízes na forma como as despesas estão estruturadas segundo a Constituição e que a situação só poderia ser contornada reformulando as despesas obrigatórias previstas nesta. Assim, a contrarreforma que teve como seu eixo central a aprovação da PEC $n^{0} 55 / 2016$, limita apenas as despesas primárias, como saúde, educação e previdência; e todas as despesas financeiras que consomem a maior parte do orçamento público são desconsideradas - como a dívida pública, por exemplo, que é responsável por mais de $45 \%$ dos gastos públicos ${ }^{4}$.

Ao contrário do que vincula a mídia hegemônica, não há um déficit contínuo e anual, nem um desequilíbrio fiscal estrutural que justifique uma medida de tamanha proporção e periodicidade. O que temos é uma estratégia de espoliação do fundo público pela burguesia rentista, tomando um papel central nas contrarreformas implementadas pelo governo golpista (ALVES, 2016), que ao lado da Reforma Trabalhista e Previdenciária, representa em um curto período de tempo uma grande perda dos direitos conquistados historicamente pela classe trabalhadora.

A justificativa de que houve um gasto descontrolado com políticas sociais que não acompanhou o crescimento do PIB é um argumento totalmente falacioso. Uma pesquisa do Departamento Intersindical de Estatísticas e Estudos Socioeconômicos (DIEESE, 2016) mostra que o crescimento das despesas com serviços públicos (ou despesas primárias) nos últimos anos esteve alinhado ao aumento da receita primária do governo e que, inclusive, os períodos em que as despesas ficaram acima da receita foram exatamente após a crise internacional de 2008, na qual o governo investiu em medidas anticíclicas para controlar a crise. Mas a partir de 2012 os efeitos da crise não puderam mais ser contornados pelo governo; houve uma estagnação do crescimento econômico do país e vivenciamos um desequilíbrio fiscal.

O novo regime fiscal restringe os gastos a todos os órgãos federais que compõem o Orçamento Fiscal e a Seguridade Social, que têm alguma autonomia financeira ou administrativa, bem como 
todos os Poderes da União. A cada ano é fixado um limite baseado na despesa primária do ano anterior corrigido pela estimativa de variação da inflação, e como essa medida terá início em 2018, significa que as despesas dos próximos 20 anos serão similares ao ano de 2017. O gasto com serviços públicos será congelado por 20 anos, independente do crescimento econômico ou das mudanças políticas ou sociais, como o aumento da população, por exemplo.

Além disso, a PEC modifica a vinculação das despesas primárias de saúde eeducação àreceita, comoprevistona Constituição, ou seja, o percentual mínimo estipulado constitucionalmente - que já era levado como gasto máximo pelos governos brasileiros - será substituído por esta lógica de limitação aos gastos do ano anterior. Se fôssemos simular a aplicação deste novo regime fiscal nas despesas primárias de 2003 a 2015, por exemplo, teríamos 47\% menos investimentos em educação e uma redução de $27 \%$ na política de saúde. (DEPARTAMENTO INTERSINDICAL DE ESTATÍSTICAS E ESTUDOS SOCIOECONÔMICOS, 2016).

O descumprimento do limite estipulado implica diversas punições, entre elas o impedimento de realização de concurso público, contratação de funcionários, criação de cargo ou função na instituição, fomento de planos de carreiras e concessão de títulos ou ajustes de salários de servidores públicos, mesmo os previstos na Constituição. Ou seja, além de usurpação dos direitos à saúde, educação, e enfim, de toda a rede de seguridade social, os trabalhadores serão os penalizados no caso de os órgãos públicos não cumprirem o teto estipulado pelo novo regime.

Os efeitos da PEC $n^{0}$ 55/2016 sobre a classe trabalhadora são os mais variados, desde a perda de direitos sociais que eram viabilizados pelas políticas sociais, que com estas medidas estão sendo sucateadas, podendo chegar ao nível de não terem recursos mínimos para atendimento da população, passando pelas restrições de ajuste na remuneração dos servidores públicos, e até mudanças no reajuste do salário mínimo. As reformas têm empreendido uma precarização do trabalho e, aliado a isso, um desmonte dos direitos sociais, para assegurar interesses de espoliação do fundo público pela burguesia rentista. (ALVES, 2016). Caso este quadro não mude, a classe trabalhadora perde com a PEC a possibilidade de disputa pelo orçamento público. 
A reforma trabalhista aprovada pelo senado federal - PL $\mathrm{n}^{\circ}$ 38/2017 (BRASIL, 2017) - no último dia 11 de julho, e sancionada pelo Presidente Michel Temer, traz mudanças ao mercado de trabalho, com um conjunto de medidas que, segundo os favoráveis, visam o aumento de vagas de emprego. Porém, essa afirmação não é consenso nem na sociedade, nem no meio político e nem no jurídico. Feita de forma aligeirada, o parlamento não considerou a discussão aberta com a sociedade, e tão pouco, com a classe trabalhadora em específico, já que é no cotidiano dessa classe que ocorrerão as mudanças.

A reforma diz trazer a modernização para as relações trabalhistas, mas na verdade, não traz nenhuma novidade, pois outros países já fizeram contrarreformas desse tipo, operando alterações nos mesmos pontos que essa. Como, por exemplo, o Reino Unido, em que dados de 2015 demonstram que não houve um crescimento no número de empregos, mas sim, contratos de trabalhos extremamente precarizados. (SAHUQUILLO, 2015). Vamos citar aqui o trabalho intermitente, aquele que é pago por horas ou produção, não caracterizando vínculo empregatício. De acordo com o Escritório Nacional de Estatística Britânico (ONS em inglês), antes da crise de 2008 era somente $1 \%$ de trabalhadores com esse tipo de contrato, apelidado de contrato de zero hora, no Reino Unido. (SAHUQUILLO, 2015). Já em 2015 o percentual era de $2,3 \%$ da força de trabalho do país; nessas condições, um total de 700.000 pessoas, dentre as quais a sua maioria era de mulheres, jovens com menos de 25 anos e idosos acima de 65 anos. Esse contrato de trabalho não determina quantas horas serão trabalhadas, nem um valor fixado para a hora trabalhada, ficando a cargo do empregador os termos, deixando o trabalhador vulnerável e sem qualquer garantia.

Dentre outras mudanças que a contrarreforma traz, podem-se citar: as demissões, que possibilitam acordos diretos com o trabalhador, dispensando a homologação no sindicato, vulnerabilizando, uma vez mais, o trabalhador; a redução da hora de almoço para 30 minutos; a carga horária, que poderá ser de até 12 horas por dia. Nesse caso, a contrarreforma prevê o direito ao descanso de 36 horas consecutivas. Foi legalizado, também, o trabalho remoto ou home office e as terceirizações para atividades fim. 
Outro ponto que prejudica o trabalhador é o fato de não ter incorporado ao salário gratificações e outros benefícios, como previdência privada e assistência médica; dessa forma, uma parte do salário pode ser paga com esses benefícios. A propaganda defendida passa pelo argumento de que vão desburocratizar as relações trabalhistas, que essa reforma irá gerar emprego, porém, o que se pode vislumbrar, de fato, é um crescimento de contratos de trabalho que não atende às necessidades dos trabalhadores, deixando-os nas mãos dos empregadores.

A referida reforma também retira todo o poder dos sindicatos, já que o que terá validade serão os acordos individuais ou coletivos, entre empregadores e empregados, ou nos termos atuais, contratados, já que essa é a tendência com a reforma trabalhista. Com relação a demissões coletivas, antes era necessária uma autorização expressa do sindicato da categoria; a partir de agora não será mais necessária essa autorização, e, para piorar esse quadro, assim que a rescisão for assinada o empregado não poderá reclamar na justiça por algum ponto que não tenha sido cumprido pelo empregador. Retira também a obrigatoriedade do imposto sindical, fragilizando os sindicatos menores. Ainda com relação à justiça, o empregado não poderá faltar a nenhuma audiência, correndo o risco de em caso de perda do pleito, ter que arcar com custos referentes ao processo.

A reforma trabalhista demonstra uma ofensiva neoliberal que tem como objetivo salvar o grande capital da crise e da queda das taxas médias de lucro. Nos governos anteriores esse processo vinha se mostrando lentamente, mas com Temer tudo foi agilizado. E em vias de ser votada, também temos a reforma da previdência, tão nociva quanto a trabalhista para o trabalhador. A reforma previdenciária foi apresentada por Temer em dezembro de 2016 e atualmente tramita na Câmara dos Deputados como PEC n ${ }^{\circ} 287$ (BRASIL, 2016b), e pretende modificar artigos da Constituição que tratam da previdência.

O argumento principal utilizado na defesa dessa contrarreforma é a existência de um déficit previdenciário, alegando-se o perigo de quebra deste sistema. Tal argumento é falacioso. Se olharmos as peças orçamentárias, poderemos constatar que a Seguridade Social é superavitária, ou seja, sobram recursos. O que acontece na prática é que a Desvinculação de Receitas da União retira recursos para o Orçamento Fiscal, sendo destinado majoritariamente a financiar 
o superávit primário. A partir de 2017 esse mecanismo passou a retirar 30\% (quando antes era 20\%) dos recursos da Seguridade. Se o mesmo não existisse, sobrariam recursos suficientes para o financiamento das três políticas que a compõem (Saúde, Assistência e Previdência Social). Além disso, o discurso de que a previdência apresenta déficit usa como dados apenas a arrecadação sobre folha de salários (empregado e empregador), comparando-a aos benefícios a serem disponibilizados. No entanto, conforme prevê a Constituição, a Previdência poderá utilizar os demais recursos da Seguridade, e isso faz com que ela jamais apresente déficit.

Os pontos da contrarreforma em questão que mais prejudicarão a classe trabalhadora, com a reforma previdenciária, serão: idade mínima e tempo de contribuição. A priori todo trabalhador, homens e mulheres, para se aposentar teriam que ter 65 anos de idade, ponto que gerou controvérsia, já que isso ignoraria a condição da mulher que cumpre dupla e às vezes tripla jornada. Por conta desse aspecto, a idade das mulheres foi reduzida para 62 anos, o que ainda é muito ruim. Quanto ao tempo de contribuição, serão necessários 49 anos para receber o valor integral do salário, e, no mínimo, 25 para o recebimento proporcional.

A contrarreforma da previdência proposta dificultará ou impossibilitará o acesso ao benefício, o que atende ao objetivo do grande capital, que é de ganhar mais consumidores para a compra da previdência privada, importante espaço de valorização capitalista em tempos de crise em função da superacumulação. O primeiro país a experimentar esse modelo de previdência foi o Chile, herança da ditadura de Pinochet. Hoje $91 \%$ da população recebem menos que $\mathrm{R} \$ 760,00$, que na moeda chilena são dois terços do salário mínimo deles. (MONTES, 2017). Quando se inaugurou esse modelo de previdência no Chile, muitos países seguiram seu modelo, tais como: Austrália, Hong Kong e outros. Desses países não temos informações, mas no Chile a população exige um posicionamento do Estado para alteração desse modelo, para um que garanta pelo menos um salário mínimo, já que o que ocorre hoje é que o trabalhador é obrigado a poupar $10 \%$ do seu salário, mensalmente, para a aposentadoria, com a promessa de receber no ato da aposentadoria o valor integral do seu salário. Mas projeções feitas pela comissão que investiga os fundos de pensão revelam que trabalhadores que contribuírem por 25 a 33 anos receberão o equivalente a $21 \%$ do seu salário na ativa. (MONTES, 2017). Esses dados nos levam a concluir que as 
saídas dadas pelo capital como solução para crises, são saídas para o abismo para o trabalhador, porque visam somente espoliar a classe trabalhadora de todas as formas possíveis e com crueldade, já que jogam os trabalhadores a margem da miséria e, em alguns casos, na própria miséria.

Em suma, além de limitar brutalmente o acesso à aposentadoria, a proposta de Temer reduz o valor dos benefícios e deixa os mais pobres absolutamente desamparados. Nada faz para reverter as benesses tributárias e fiscais concedidas aos grandes empresários, que tanta falta fazem ao caixa da previdência social. Também nada faz quanto aos grandes sonegadores, que criminosamente tiram dinheiro da seguridade social.

O objetivo não declarado da reforma da previdência é o de enfraquecer a previdência pública, empurrando os trabalhadores para os braços dos bancos e seus fundos de previdência privada. $\mathrm{O}$ desmonte do Estado, que começou com a $\operatorname{PEC~} n^{\circ} 55 / 2016$, prossegue com a reforma da previdência, destruindo o sonho de construir uma sociedade mais justa e solidária, o substituindo pelo objetivo dos grandes bancos de lucrar cada vez mais com as necessidades e aspirações do povo brasileiro.

\section{CONCLUSÃO}

Vivemos atualmente uma avalanche conservadora e reacionária que tem fortes e cruéis impactos no mundo do trabalho e no que se refere aos direitos sociais. O saldo de um ano de golpe, perpetrado em abril de 2016 e concluído em agosto daquele ano, o que vemos é um conjunto de medidas que retrocedem no campo dos direitos historicamente conquistados. A crise do capital, que se iniciou em 2008, atingindo os países centrais, chega nos últimos anos aos países da América Latina, e, no Brasil, se potencializa com a crise política instaurada desde 2013 e aprofundada com as denúncias de corrupção. A reacomodação do bloco de poder dominante pósgolpe visa aprofundar as medidas de ajuste fiscal para saída da crise.

A saída imediata buscada pelo capital e capitaneada pelo governo golpista tem sido a redução e/ou eliminação de direitos históricos por meio das contrarreformas. Se não é novo esse processo, nos últimos tempos tem se apresentado de forma ainda mais perversa e rápida. As contrarreformas das políticas sociais são mecanismos de captura do fundo público pelo capital para a 
retomada dos superlucros em tempos de crise. Tais contrarreformas só podem ser caracterizadas pela usurpação dos nossos direitos, pela vampirização da riqueza que os trabalhadores produzem a favor da lucratividade do capital.

Os ataques do governo golpista à redução da arrecadação de recursos para as políticas sociais e dissolução dos direitos históricos conquistados, em especial no âmbito da Seguridade Social e educação, além das consequências concretas e imediatas que trarão para execução dessas políticas, têm o objetivo de mercantilizar os direitos do trabalho como espaços de retomada dos lucros do capital em tempos de crise. Não é por acaso que o grande capital financeiro está presente na educação privada, na previdência privada, na saúde etc.

Se vivemos intensos ataques nesse último ano, as diversas mobilizações realizadas abrem caminho para a intensificação da unidade entre os movimentos sindicais e sociais, na perspectiva de barrar esses ataques. Nós, trabalhadores, precisamos dar uma resposta à altura para o governo golpista de Temer e sua base aliada. É fundamental a mobilização organizada, no sentido de mostrar à sociedade brasileira que só nas ruas podemos barrar os ataques.

Nossa alternativa deve ser criar as condições para barrar as reformas, seja por qual meio venham a se impor. Nosso dever é afirmar que a crise atual indica o limite da democracia existente na forma da representação pelo voto e que se faz urgente uma nova forma de política. Os conflitos na coalizão golpista demonstram que a burguesia nunca esteve tão fragmentada e abrem uma brecha para a mobilização democrática e cidadã. A luta contra os ataques que vivenciamos é uma luta pelo fundo público, pelos direitos dos trabalhadores, pela construção de um regime de democracia mais intensa e de maior abertura ao interesse popular.

\section{REFERÊNCIAS}

ALVES, G. A PEC 241, a contrarreforma neoliberal e a Tragédia de Prometeu. Blog da Boitempo, São Paulo, 9 out. 2016. Disponível em: <https://blogdaboitempo.com.br/2016/10/19/a-pec-241-a-contrareforma-neoliberal-e-a-tragedia-de-prometeu/>. Acesso em: 16 jul. 2017. 
ANDERSON, P. Balanço do neoliberalismo. In: SADER, E.; GENTILI, P. (Org.). Pós-neoliberalismo: as políticas sociais e o Estado democrático. Rio de Janeiro: Paz e Terra, 1995. p. 9-23.

BEHRING, E. R. Brasil em Contra-reforma:desestruturação do Estado e perda de direitos. 2. ed. São Paulo: Cortez, 2008.

Crise do capital, fundo público e valor. In: BOSCHETTI, I. et al (org). Capitalismo em crise, política social e direitos. São Paulo: Cortez, 2010. p. 13-34.

BRASIL. Câmara dos Deputados. Proposta de Emenda a Constituição 287/2016. Altera os artigos 37, 40, 109, 149, 167, 195, 201 e 203 da Constituição, para dispor sobre a seguridade social, estabelece regras de transição e dá outras providências. Brasília, DF, 5 dez. 2016 b.

Emenda Constitucional n ${ }^{\circ} 95$. Altera o Ato das Disposições Constitucionais Transitórias, para instituir o Novo Regime Fiscal, e dá outras providências. Diário Oficial da União, Brasília, DF, 16 dez. 2016a. Seção I, ano CLIII, n. 241.

Lei $n^{\circ} 13.467$, de 13 de julho de 2017. Altera a Consolidação das Leis do Trabalho (CLT), a fim de adequar a legislação às novas relações de trabalho. Diário Oficial da União, Brasília, DF, 14 jul. 2017. Seção I, ano CLIV, n. 134.

DEMIER, F. A revolta a favor da ordem: a ofensiva da oposição de direita. In: _ ; HOEVELER, R. (Orgs.). A onda conservadora: ensaios sobre os atuais tempos sombrios do Brasil. Rio de Janeiro: Mauad, 2016. p. 51-56.

DEPARTAMENTO INTERSINDICAL DE ESTATÍSTICAS E ESTUDOS SOCIOECONÔMICOS. PEC n ${ }^{\circ}$ 241/2016: o novo regime fiscal e seus possíveis impactos. Nota Técnica, São Paulo, n. 161, set. 2016. Disponível em: $<$ http://www.dieese.org.br/notatecnica/2016/ notaTec161novoRegimeFiscal.pdf $>$. Acesso em: 17 jul. 2017.

IASI, M. Democracia de cooptação e apassivamento da classe trabalhadora. In: SALVADOR, E. et al. (Orgs.). Financeirização, fundo público e política social. São Paulo: Cortez, 2012. p. 285-317.

MANDEL, E. Capitalismo Tardio. São Paulo: Abril Cultural, 1982.

MARX, K. O Capital: crítica da economia política. São Paulo: Abril Cultural, 1983. Livro 3. Tomos 1 e 2.

MONTES, R. Modelo pioneiro de previdência privada adotado no Chile enfrenta crise. El país, Madrid, 18 fev. 2017. 
Giselle Souza | Isabel Cristina Lopes Barbosa

Edite Alves Azevedo | Hugo Cordeiro Mota Pinheiro

Disponível em:<https://brasil.elpais.com/brasil/2017/01/17/

internacional/1484673838_832258.html>. Acesso em: 19 jul. 2017.

OLIVEIRA, F. de. Os Direitos do Antivalor: a economia política da hegemonia imperfeita. Petrópolis, RJ: Editora Vozes, 1998.

SAHUQUILLO, M. R. Trabalhadores ultraflexíveis. El país, Madrid, 3 mai. 2015. Disponível em:<https://brasil.elpais.com/brasil/2015/05/01/ internacional/1430504838_853098.html>. Acesso em: 19 jul. 2017.

\section{Notas}

1 Utilizamos a categoria contrarreforma (BEHRING, 2008) para marcar o caráter regressivo das reformas neoliberais no que diz respeito aos direitos sociais e trabalhistas.

2 Este artigo faz parte dos estudos parciais realizados pelo projeto de pesquisa em andamento na Universidade Federal do Estado do Rio de Janeiro (UNIRIO), iniciado em maio de 2017, cujo título é Fundo público e Estado no Brasil contemporâneo: crise do capital e os impactos para as políticas sociais.

3 Para aprofundamento de debate crítico sobre o novo desenvolvimentismo dos governos petistas ver: Revista Serviço Social e Sociedade, n. 112, 2012. Disponível em: $<$ http://www. scielo.br/scielo.php?script $=$ sci issuetoc $\&$ pid $=0101-662820120004 \& \operatorname{lng}=$ pt\&nrm $=$ is $>$. Acesso em: 19 jul. 2017

4 Em função da pressão popular em torno das contrarreformas que originaram diversas mobilizações em 2016 levaram a uma mudança na proposta original, e agora no caso das áreas de saúde e educação, as mudanças só passariam a valer após 2018. 